
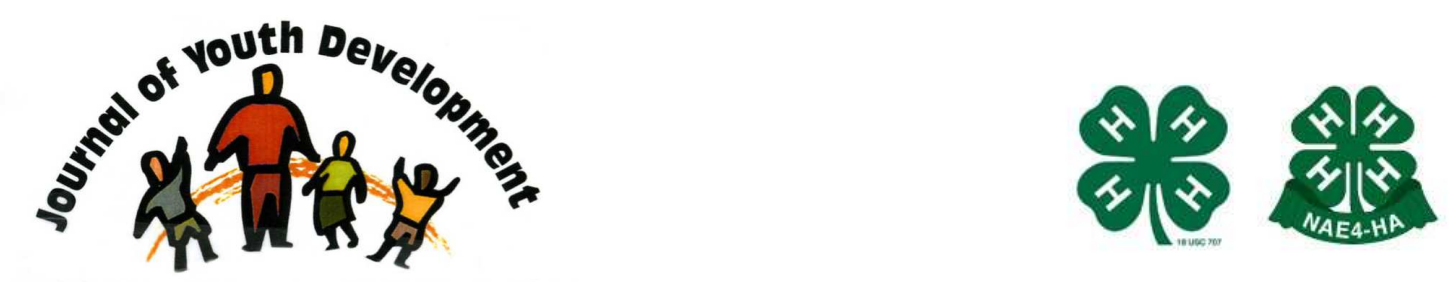

Bridging Research \& Practice

\title{
Evidence of Self-Directed Learning on a High School Robotics Team
}

\author{
Nathan R. Dolenc \\ University of Virginia \\ Charlottesville, VA \\ nrd3fp@virginia.edu
}

\author{
Claire Mitchell \\ Albion College \\ Albion, MI \\ cmitchell@albion.ecu
}

Robert H. Tai

University of Virginia

Charlottesville, VA

rht6h@virginia.edu 


\title{
JOURNAL OF YOUTH DEVELOPMENT \\ bridging research and practice

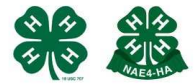

Volume 9, Number 4, Winter 2014

Article 140904PA001

\section{Evidence of Self-Directed Learning on a High School Robotics Team}

\author{
Nathan R. Dolenc and Robert H. Tai \\ University of Virginia \\ Claire Mitchell \\ Albion College
}

\begin{abstract}
Self-directed learning is described as an individual taking the initiative to engage in a learning experience while assuming responsibility to follow through to its conclusion. Robotics competitions are examples of informal environments that can facilitate self-directed learning. This study examined how mentor involvement, student behavior, and physical workspace contributed to self-directed learning on one robotics competition team. How did mentors transfer responsibility to students? How did students respond to managing a team? Are the physical attributes of a workspace important? The mentor, student, and workplace factors captured in the research showed mentors wanting students to do the work, students assuming leadership roles, and the limited workspace having a positive effect on student productivity.
\end{abstract}

\section{Introduction}

Self-directed learning is described as an individual taking the initiative to engage in a learning experience while assuming responsibility to follow through to its conclusion. The focus of this case study was to examine evidence of self-directed learning (SDL) among students and their mentors on a high school robotics competition team. Research has found that SDL is connected with continued development of individuals into life-long learners who also appear to accept greater responsibility for their own learning (Abraham, Upadhya, \& Ramnarayan, 2005). In addition, other researchers have found that self-directed learners appear to have a greater awareness of their own learning (Garrison, 1997) and appear to feel empowered to monitor their own progress within a learning activity (Ellinger, 2004). According to Knowles (1975), selfdirected learners inquire and research new content knowledge that they are curious about and are willing to take on new challenges and solve difficult problems. Long (1990) also found self- 
directed learners to be persistent and independent. It seems reasonable to say that some degree of SDL could exist in most learning situations, formal or informal (Guglielmino, 2008).

Robotics competitions are examples of informal learning environments that can facilitate student SDL. In recent years, robotics programs have become popular across the $\mathrm{K}-12$ spectrum, e.g. FIRST ${ }^{T M}$, Vex ${ }^{T M}$, and Bot Ball ${ }^{T M}$. Research has found a number of positive associations between participation in robotics learning activities and science process skills as well as students' attitudes toward science (Bers, \& Portsmore, 2005; Mataric, Koeing, \& FeilSeifer, 2007; Welch, 2010).

However, constructing a robotics program with the goal of creating conditions for studentfocused SDL to occur requires not only student participation but also adult mentors possessing a working knowledge of pedagogy and an environment conducive to learning. Mentor involvement plays an important role in robotics programs as their level of guidance and directive may impact students' self-directed behavior. Additionally, the physical environment can influence engagement and contribute to student-focused SDL (May, Gilson, \& Harter, 2004).

The goal of this study was to examine if, and how three factors (mentors' role, student behavior, and physical characteristics of a work environment) support the existence of student SDL on a high school robotics team. An examination of these three factors may inform researchers and practitioners in out-of-school time (OST) STEM education fields about the mechanisms associated SDFL and how to better foster SDL on the part of students.

We sought to address the following research questions:

1. What roles and behaviors do mentors take that contribute to student self-directed learning on a robotics program?

2. How, if at all, does student behavior align with characteristics of self-directed learning?

3. What facets of the physical work environment contribute to student self-directed learning?

\section{Framework}

This case study examined one high school robotics team that we refer to as "Team Faraday," to answer our research questions. In order to make sense of the data collected, we applied a selfdirected learning theory to gain greater insight into how Team Faraday's mentor involvement, student behavior working together, and the physical working environment contributed to building their robot and achieving their goals.

\section{Self-Directed Learning Theory}

In this study, we used a self-directed learning theory lens to focus on the individual students as the learners. Through this lens, learners are expected to learn autonomously and assume responsibility for their own progress (Caffarella, 1993). SDL emphasizes that learners take up independent roles in setting their own goals and employing strategies to reach those goals (Garrison, 1997). It is achieved when the appropriate experiences, encouragement, and learning tools and resources are present. SDL does not equate to working alone as it often requires learners to work in collaboration, to self-manage social settings and resources, and to take actions that regulates their own cognitive learning strategies (Garrison, 1997; Merriam, Caffarella, \& Baumgartner, 2012; Khodabandehlou, Jahandar, Seyedi, \& Abadi, 2012). 
The role of a teacher, or in this case stay, a mentor, in the SDL process is to act as a facilitator cultivating the learner's ability to learn instead of assuming they have the responsibility for what and how the learner should be taught (Grow, 1991). Mentors may contribute to student learning by being a point-of-reference, organizing meetings for students to discuss current challenges and issues, or even encouraging students to monitor and evaluate their own method of progress.

\section{Methods}

Qualitative case study methodology was used to conduct an in-depth exploration of a single high school robotics team during their six-week building season (Stake, 1995). We searched for matching patterns between the SDL framework and the factors of mentoring involvement, student behavior, and the physical working environment as a way of relating data to a proposition, which is often seen in case studies (Yin, 2009).

\section{Team Settings and Participants}

In the year of this study, Team Faraday was in its sixth year overall, but only in its third year as a community-based team after breaking away from what mentors called "the bureaucracy of a school-based team." In the formation of their community-based team, meaning they accepted students from a variety of schools, they found basement space in an administration building of a different school to use for their workspace. Team Faraday was located on a campus of a private boarding school located in a rural mountain town in the northeast United States. The adult leaders converted a small photography lab into a workspace that housed their computers, electrical equipment and setup area, and small table machinery. The hallway leading to their workspace and two nearby even smaller music rooms were occasionally used for breakout or small group discussions.

The team consisted of twenty high school students and six mentors. Eleven of the students were boarding students from the on sight private school with the other nine students from two public schools in nearby towns. Three of the students were female. All students were Caucasian except one female student was African American. Team Faraday did not have a significant age concentration making for a more even split of students across the four high school grade levels. The six mentors on Team Faraday had background and career experience in information technology, computer science, mechanical and electrical engineering, and community service. Their background and content knowledge equipped them with a familiarity needed in facing most challenges in designing and building a robot for competition.

The year of this study, in 2012, the not-for-profit company responsible for organizing the competition challenged teams to design and build a robot to compete in a game that involved shooting foam basketballs and balancing on teeter-totter bridges. In order to score points, robots needed to be designed to shoot or place foam basketballs through one of four hoops positioned at three different heights: a low level hoop, two medium level hoops, a high level hoop. The higher the hoop the more points were awarded. Teams could also score points by designing their robot to balance on a teeter-totter bridge. If teams managed to balance with other robots in the game they were awarded bonus points.

Team Faraday had six weeks to design and build a robot before they were required to seal their robot in a giant plastic bag. Once sealed and time stamped, they could not open their robot again until their regional competition. The team met during the six week building season 
Monday through Saturday. Meetings lasted for five hours after school during the week and six hours on Saturday.

\section{Data Sources and Analytical Approaches}

Team Faraday was selected due to its sufficiently rich data that highlighted mentors', students', and the workplace environment's contribution to student SDL on a high school robotics team (Polkinghorne, 2005). Data were collected from both first-person observations and interviews of participants during their building season. Pseudonyms were used for the names of the mentors, students, and the team who participated in this study.

In-person observations were conducted during one six-hour team working session. Observations focused on mentor involvement, mentor and student interactions, student behavior, team actions toward completing tasks, and comments made during work. Data collected from observations were used to explain our research questions through matching patterns with SDL framework. Observations focused on confirming mentors acting as facilitators rather than assuming responsibility, students assuming responsibilities for decision making, and how the physical environment contributed to student engagement, as posited by SDL theory.

Interviews with mentors and student members were also conducted, recorded, transcribed, and later confirmed by the interviewee. The lead mentor was interviewed by phone prior to inperson observations. All other mentors and students were face-to-face interviews conducted on-site. Mentors and students interviewed on-site stepped away from their current task to be interviewed. Along with the lead mentor, two other mentors were also interviewed on-site. Four students from Team Faraday were interviewed, and were selected based on their held leadership positions. Mentors and students were asked the same series of open-ended questions beginning with the interviewee being asked to explain the robotics game and what kind of robot they were building. The interview continued by inquiring about their initial interest in robotics, what their responsibilities were on the team, how their robotics team was structured and functioned, and what they, the students and mentors, were gaining by being on their robotics team. Interviews were flexible to explore further areas of interest that appeared during the interview in addition to answering the series of predetermined questions. In addition, impromptu questions were asked to mentors and students who appeared to step back from their line of work during their working sessions. These impromptu questions captured real time responses and immediate reflections and real time regarding the on going planning, progress, and work of the team. As with our observations, interview data collected was used to explain our research questions through our SDL frameworks lens.

Our SDL framework shaped how we coded the observational and interview data. Coding resembled the three factors discussed in this study in detail: mentor involvement, student behavior, physical characteristics. Coding for mentor involvement involved combing the data for how mentors worked with students, what challenges they had with students, what they felt students on their team were gaining by designing and building a robot, and what mentors viewed as their teaching vision or philosophy. Coding for student behavior looked for levels of student engagement, responsibility, and decision making on their team, ways in which students interacted with their mentors and peers, and reasons for their interest in being on a robotics competition team. Coding for physical characteristics involved examining descriptions of the workspace and how team members interpreted their space. The themes that emerged from the data fell under the SDL framework and gave rise to evidence that were used to support answers to our research questions. 


\section{Findings}

The following section presents evidence of student-focused SDL from the perspective of the mentor involvement, student behavior, and physical workspace on Team Faraday.

\section{Mentor Involvement}

The mentors on Team Faraday described their desire to move the balance of the working relationship between themselves and the students to a format of having students do most of the decision-making and work toward building their robot. They expressed concerns that mentors who possessed a highly directive nature toward their students would lead to a scenario where students were not learning. Encapsulating this, Andy, a mentor on Team Faraday, explains their team's mentoring approach:

"If you take somebody and you try to teach them how to do something, about the fourth iteration they start unlearning it. This is occasionally called 'drill and kill.' If you teach somebody how to do something by doing it with them and then you back off and let them do it and then go through a Q/A [quality assurance] process with them, which is teaching another important skill, that you always check your work with yourself and another person, then they know it forever. You're guiding self-teaching. You're helping them learn it themselves...people learn better by doing."

Mentors displayed characteristics of contributing to a SDL environment by acting as guides or facilitators while encouraging students to take the lead in working on their robot. They also promoted to students the importance of monitoring their progress by checking their own work. Beth, a mentor, states, "If you don't know how to do it, we will show you how to do it. We want the kids to do it."

As part of their 'taking a step back' approach, mentors routinely allowed students to make mistakes and experience failure. Beth describes a former student on the team learning through failure about certain materials for their robot:

"There was this one girl who was insistent that she was going to use acrylic to make this shield. And, acrylic is really brittle. She cut it thirteen times before she finally realized and said, 'You know, I think I need to use something else,' but those are the things the kids still remember and talk about."

The working environment the mentors created was safe and allowed room for students to experiment, explore their own ideas, and make mistakes. They maintained this even though they understood and felt the challenges of creating such an environment as they saw their students make mistakes without stepping in. Andy expresses this effort by saying, "The hardest thing as a mentor is that you have to be able to back off and go 'Ok, let them learn. "'

There were several positive student outcomes the mentors believed were associated with their approach to working with their students. They saw improvements in students' self-confidence, abilities to work in groups, and creativity. Beth and Andy describe what the students are gaining on their team:

Beth: "There's a lot of growing up they would do anyway going from a fourteen year old to an eighteen year old, but the robotics program gives them an incredible amount of self-confidence. Because it's such a huge project for them that when they come out 
on the other side, having accomplished this, no matter how big of a role that they have they feel like they can accomplish anything."

Andy: "Creativity comes out of this because a creative person will look at a problem and especially when they've hit that engineering brainset and it starts to tick over they'll start figuring out an easier way to do it or a better way to do it or a more efficient way to do it and they'll start looking for ways to apply what they know before to this and you [mentors] kind of want to just fan that fire, you want to make it grow."

The mentors on Team Faraday took steps to ensure students were making the decisions and doing the work on the team's robot. They acted as a person-of-resource stepping in when students wanted to learn how to do something and as a guide asking leading and confirmatory questions to help students monitor their work. Mentors also saw the benefits of students taking responsibility for the work that need to be completed as they knew these skills would help the students develop and grow as individuals and as a team.

\section{Student Behavior}

Students quickly adapted to taking over responsibilities and opportunities. They expressed an eagerness to make the tasks at hand their own as they led discussions about particular issues, solved problems that suddenly appeared, and progressed forward with building their robot design mostly without a mentor's aid. Students only referred back to mentors when they had completed a task and were looking for another, more experienced person to check their work. Overall, they realized mentors played a large role on their team, but checked in with them when help was needed or to review their completed work.

\section{Solving a Frame Mistake: A Narrative}

The following is a narrative describing how students, while working on their robot frame, discovered a problem and solved it. The narrative is an example of students displaying SDL as they self-managed themselves and took initiatives to solve the problem.

Five students gathered in the center of the room to inspect their newly arrived frame, which now sat on two metal saw horses. The sole mentor in the room stood back to watch and listen. The team had outsourced the labor of welding their metal frame to a local business, and now, they were eager to assemble their robot. The students were discussing where the pneumatic cylinder devices would be placed on the frame in order to lower their omni drivetrain down far enough to raise the entire robot slightly off the ground, disengage the standard drivetrain, and allow the robot to move in any direction. Their conversation quickly turned to mathematics as a couple of students chimed in with calculations for solving the problem. While the conversation was slowly escalating in volume, a sixth student sitting in front of a desktop computer with a computer assisted drawing (CAD) had his head on a swivel looking back and forth between the drawing and the robot. He got up out of his chair, found a measuring tape, and forced his way to the robot to measure its width. He then delivered some bad news. The frame was an inch and a half wider than originally designed. The students now had the dual problems of finding the vertical and horizontal locations to place the pneumatic cylinders. The mentor continued to stand back and watch events unfold in front of him. Jason, a mentor, mentioned, "My objective each year is to not pick up a tool. I fail every year because someone usually ends up needing help, but I want to take a sitting-on-hands approach." 
Frustrations were mounting as the students were trying to comprehend the issue and develop working solutions to fix the problem. A couple of students gave quick suggestions, but no solutions were agreed upon. Some students knew the welding mishap to be part of a larger problem and could lead to further problems down the line. Brian, the student team captain, knew of this issue:

"Space on the robot is our biggest challenge this year because, you know, we have so many different mechanisms on the robot. We have a way to get the balls into the robot, a way to shoot them, and then of course our drivetrain. Then we have all the electronics stuff, and it's always a challenge, but it's really been a challenge this year. And once we hopefully all figure it out of course the next challenge is weight because we have a maximum weight limit. So, that's going to be a big challenge for us to see if we make that weight limit and if we don't...It's happened before where we've exceeded the weight limit but we just have to figure out how we don't."

The students finally decided to suspend the cylinders on metal clamps instead of mounting them directly to the internal portion of the frame as originally planned. This would allow the omni drivetrain to be lowered properly and still not add too much additional weight to the robot. As the decision was made, the mentor stepped in for a moment to ask confirmatory and guided questions about where the drill holes were going to be placed and how they were going to attach the cylinders. The mentor nodded as one student answered his questions, and eventually stepped back to let the students continue their work.

The narrative gives evidence to support of the existence of a student-focused SDL environment. Students assumed it was their responsibility to assemble the robot once the frame returned to their workspace. Their self-direction led them to discuss in groups what needed to be assembled, address problems, make and evaluate suggestions, and agree upon a solution. Students were able to self-manage themselves and available resources in a social setting that required them to assemble parts of a robot together.

\section{Governing Themselves}

Students took actions to ensure their team would be student-focused by creating an internal student council to govern and manage the day-to-day work themselves. Brian explains efforts made in the past that led to their student focused team structure:

"We had a problem with a mentor trying to do everything, and freaking out at kids who wouldn't work or wouldn't be here every day and was basically being way too controlling. He wasn't teaching, wasn't mentoring. He was basically in it for himself...After that we split off from him and made a bunch of ground rules and basically wrote a team handbook and bylaws. We did that basically to protect the team and to make sure as much of the team work is done by the students. The mentors have a huge role in the team, but their role is not to be the team. It's to mentor and guide. Make sure we are safe."

The creation of the student council placed management, direction, and the decision making power of the team into the students' hands. Although students viewed the role of their mentors was to supervise and provide guidance, they felt any decision that directly impacted the strategy, design, and construction of the robot ought to be in the hands of the students. 
Since the students were managing the team, they took it upon themselves to educate team members on aspects of the robot. This included passing down knowledge from veteran, more experienced students to rookie, less experienced students, creating a kind of institutional knowledge. Older students taught younger students about parts of the robot, programming language, and methods of constructing a robot in order to bring them up to speed so they could also contribute to the team. Seth, the team treasurer, describes what occurred to prepare younger students for the build season:

"One of the neat things is that at the competition judges come around and they can ask anyone on the team questions. So you just can't have a few people who know what they are doing. So, before the competition started, before we even got our challenge a bunch of the old team members sat down all the people new to the team with last year's robot and showed them all the key parts and how it worked... We got the challenge in January but in early December we were already working to get everyone on the same page."

Team Faraday knew having every team member educated on features of the robot would benefit the entire team and allow younger students to enhance their own skills. Students were aware of the constant rotation of students coming onto the team early in high school and leaving later on, but took it upon themselves to ensure knowledge was being passed down to the next generation of students. In this sense, the more advanced students themselves took roles left by the mentorship vacuum.

Student behavior also showed them taking active roles to adapt prior knowledge to their new robot design and learn skills new to the team. A pair of veteran students with previous experience of working on the wiring and electrical components of their robots designed their electrical board to adapt to their already crowded internal portion of the robot. Also, Jake, a rookie on the team, took it upon himself to learn a CAD program previously not used be the team saying that: "I'm taking an independent study at school learning Solidworks because our design mentor left the team."

The students on Team Faraday showed ample signs of SDL by self-managing themselves, teaching and passing knowledge down to new members, taking initiatives to complete tasks, and learning new skills that would help themselves and the team. Students' relationships with mentors resembled seeking counsel when unaware of how to perform certain tasks or needing reaffirmation of completed work.

\section{Physical Workspace}

The analysis of the physical space showed it to contribute to the productivity of Team Faraday. Although cramped, the workspace generated a productive working environment as teammates had only one choice while in the room: to work. Andy interprets the confined space as an advantage, "It's not so much the coziness but the openness of the room. There are no walls to hide behind." In this sense, the physical proximity led to greater engagement.

The lack of space forced mentors and students to utilize every inch of the approximately 250 square foot converted photography lab. The left side and middle of the room were used for building and assembling the robot. The waist high counter running along the left wall had a bench grinder, a lathe, a wooden three drawer toolbox, and a 6 inch vise grip. This section had signs of heavy use as hand tools, drill bits, nuts and bolts, metal shavings, a set of wheels, small metal frame pieces, and safety goggles were intertwined with the machinery equipment in 
no apparent order. The right side of the room housed the electrical and programming equipment. The robot's electrical board and camera equipment used for aligning and shooting in game play sat on a chest high counter in the right back corner of the room. Another waist high counter ran the length of the right wall where sat a laptop computer for programming and two more desktop computers used for running CAD software. Two whiteboards were mounted above the three computers, and were filled with notes and drawings of strategies, robot designs, and programming code.

The high level of productivity in close quarters also meant team members had to be aware of safety issues. Beth states,

"It's a relatively small room. It can hold about fifteen people, but there's a chop saw, vise grip, and a drill and someone is always trying to sneak by. There's a lot of stuff going on, and they are teenagers. They need to be aware for safety reasons."

However, students embraced the close quarters nicknaming it "The Bat Cave," and made the most of their limited space by squeezing all of their robotics resources into the room. The students thought the small size of the room played an important role. Jake says, "It is an advantage. I mean, we are close and we sort of know more or less what everyone else is doing. "The small confines of the workspace helped students form a more cohesive team in which they relied on each other, thus developing more SDL skills.

\section{Discussion and Conclusion}

The analysis of the observational and interview data of Team Faraday matched definitions of SDL. Mentors placed the onus of designing and building the robot on the students. In addition, they acted as facilitators asking guiding questions in order for students to make progress and evaluate their own work. Students took advantage of these responsibilities by taking ownership over designing and building their robot. They also took steps to self-govern themselves that had broad impacts on limiting mentor involvement and proliferating student engagement. In regards to the small physical space, students working in close proximity raised the team's productivity level. The findings in this study revealed signs of students being self-directed learners by showing initiative and deeming it their responsibility to acquire knowledge in order to progress through building their robot (Abraham, Upadhya, \& Ramnarayan, 2005).

There appeared to be a fourth factor contributing to student SDL. This fourth factor is the robotics challenge itself. The organization's stated mission was to motivate students by engaging them in a hands-on science and engineering robotics activity that involved building a robot during a six week period and then competing in front of thousands of people over the course of three days (Welch, 2010). Students on Team Faraday were interested and motivated by the challenges the organization had planned for the competing teams. 
Figure 1

Factors Contributing to Self-Directed Learning
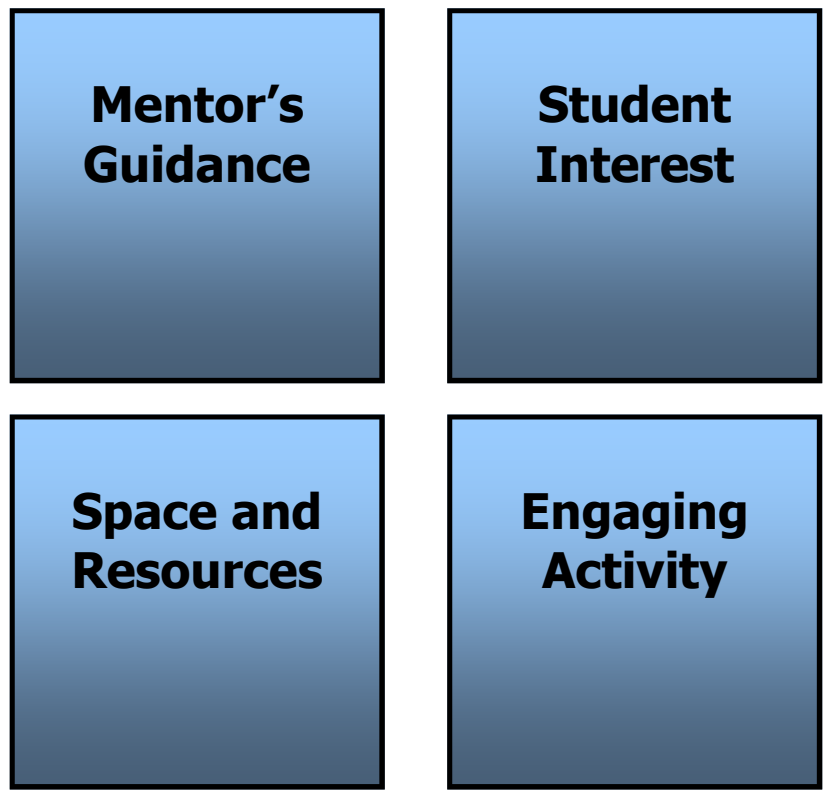

Adult supervision, student interest in science and engineering, available space and resources, and the robotics activity were the components needed to make this OST program possible. However, student SDL on Team Faraday might have been in jeopardy if one of these factors, in the form they took in the year of this study, was absence. Adult mentor supervision could have taken a more authoritarian approach by assigning specific tasks to student while turning away more self-directed students. These mentors did not create these types of barriers but instead allowed students to gain first-hand experience with technical challenges and encouraged them to participate and monitor their own work. Additionally, while it may be presumed that students selected to participate on Team Faraday for a variety of reasons, it was evident from their active engagement in acquiring knowledge to program, design, and assemble their robot that team members were invested in this activity. Team Faraday appeared to have the appropriate ratio of space and resources to number of students participating. A much larger team may have needed more space in order to keep students engaged. However, evidence showed their small space had a positive effect on students' productivity. Finally, the robotics activity was engaging for students. We may have seen lower levels of student engagement had the robotics challenge been poorly designed. This was not the case as evidence showed students engaged designing and building and foam basketball shooting robot in preparation for the competition.

This study examined an individual case where four factors contributed to the development of a student-focused SDL environment. These four factors may be used as points of comparison with other OST robotics teams. However, we discourage the use of these factors as a means of "labeling" programs as less conducive to SDL than another program, since, variations of these factors may exist on other teams and still create an SDL environment. Rather, these factors offer platforms upon which variations in practice may be studied, compared, and contrasted. Further examination of mentoring styles, student interests and behavior, available resources, and engagement in the year-to-year robotics challenge on other robotics teams is needed if researchers and practitioners are to better understand the development of SDL in these OST robotics programs. 


\section{References}

Abdullah, M.H. (2001). Self-Directed Learning. ERIC Digest.

Abraham, R.R., Upadhya, S., \& Ramnarayan, K. (2005). Self-directed learning. Advances in physiology education, 29(2), 135-136.

Bers, M.U., \& Portsmore, M. (2005). Teaching partnerships: Early childhood and engineering students teaching math and science through robotics. Journal of Science Education and Technology, 14(1), 59-73.

Caffarella, R.S. (1993). Self-directed learning. New directions for adult and continuing education, 1993(57), 25-35.

Ellinger, A.D. (2004). The Concept of Self-Directed Learning and Its Implications for Human Resource Development. Advances in Developing Human Resources 2004 6: 158

Garrison, D.R. (1997). Self-directed learning: Toward a comprehensive model. In Adult Education Quarterly, Volume 5, Number 1, Fall 1997.

Grow, G.O. (1991). Teaching learners to be self-directed. Adult education quarterly, 41(3), 125149.

Guglielmino, L. (2008). Why Self-Directed Learning? International Journal of Self-Directed Learning Volume 5, Number 1, Spring 2008.

Khodabandehlou, M., Jahandar, S., Seyedi, G., \& Abadi, R.M.D. (2012). The Impact of Selfdirected Learning Strategies on Reading Comprehension. International Journal of Scientific \& Engineering Research, 3(7), 1.

Knowles, M.S. (1975). Self-directed learning. New York: Association Press.

Long, H.B. (1990). Psychological control in self-directed learning. International Journal of Lifelong Education, 9(4), 331-338.

Mataric, M.J., Koenig, N., Feil-Seifer, D. (2007). Materials for Enabling Hands-On Robotics and STEM Education. AAAI Spring Symposium on Robots and Robot Venues: Resources of AI Education. March, 2007. Stanford, CA.

May, D.R., Gilson, R.L., \& Harter, L.M. (2004). The psychological conditions of meaningfulness, safety and availability and the engagement of the human spirit at work. Journal of Occupational and Organizational Psychology, 771), 11-37.

Merriam, S.B., Caffarella, R.S., \& Baumgartner, L.M. (2012). Learning in adulthood: $A$ comprehensive guide. John Wiley \& Sons.

Polkinghorne, D.E. (2005). Language and meaning: Data collection in qualitative research. Journal of counseling psychology, 52(2), 137.

Stake, R.E. (1995). The art of case study research. Thousand Oaks, CA: SAGE, Inc. 
Welch, A.G. (2010). Using the TOSRA to Assess High School Students' Attitudes toward Science after Competing In the FIRST Robotics Competition: An Exploratory Study. Eurasia Journal of Mathematics, Science \& Technology Education, 6(3), 187-197.

Yin, R.K. (2009). Case Study Research: Design and Methods. Thousand Oaks, CA: SAGE, Inc.

(c) Copyright of Journal of Youth Development $~$ Bridging Research and Practice. Content may not be copied or emailed to multiple sites or posted to a listserv without copyright holder's express written permission. Contact Editor at: patricia.dawson@oregonstate.edu for details. However, users may print, download or email articles for individual use.

ISSN 2325-4009 (Print); ISSN 2325-4017 (Online) 
